\title{
On Projectiles
}

\section{Michael Scott Esq., C.E.}

To cite this article: Michael Scott Esq., C.E. (1866) On Projectiles, Royal United Services Institution. Journal, 10:40, 290-302, DOI: 10.1080/03071846609417203

To link to this article: http://dx.doi.org/10.1080/03071846609417203

\section{册 Published online: 11 Sep 2009.}

Submit your article to this journal

LII Article views: 2

Q View related articles $\sqsubset$ 
otherwise burst in the hand and destroy the person. My percussion grenade has no fuze to be lighted, and

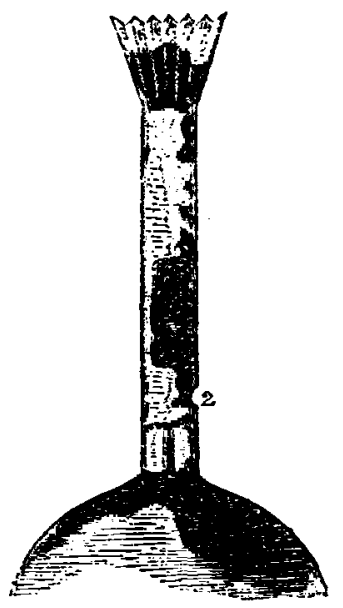

1. Ieaden bolt for pulverizing glass tube.

2. IIoln for inserting glass tubc holder.

of falling on the ground explodes the grenade.

Annexed is a drawing of the winged tube containing the glass tube igniter, and which is screwed into the iron grenade.*

\section{ON PROJECTILES.}

\section{By Mrchatel Scotr, Esq., C.E.}

With the permission of the meeting the anthor, proposes on the present occasion to confine his observations mainly to a class of projectiles which may be said to occupy an intermediate place between spherical shot and elongated rifle bolts.

In the year 1862 the writer published a pamphletf in which he explained a principle whereby the want of homogeneity in elongated projectiles might be obviated, and in which he stated that the centre of gravity being corrected, and the projectile made symmetrical, it would not deviate from the true line of flight, eren although not rotating upon its axis.

* They can bo obtained at Mr. Calderwood's, Gunmaker, Sackvillo Strect, Dublin.

† On Projectiles and Guns. By Michael Scott, C.E. Clowres and Son, Charing Cross. 

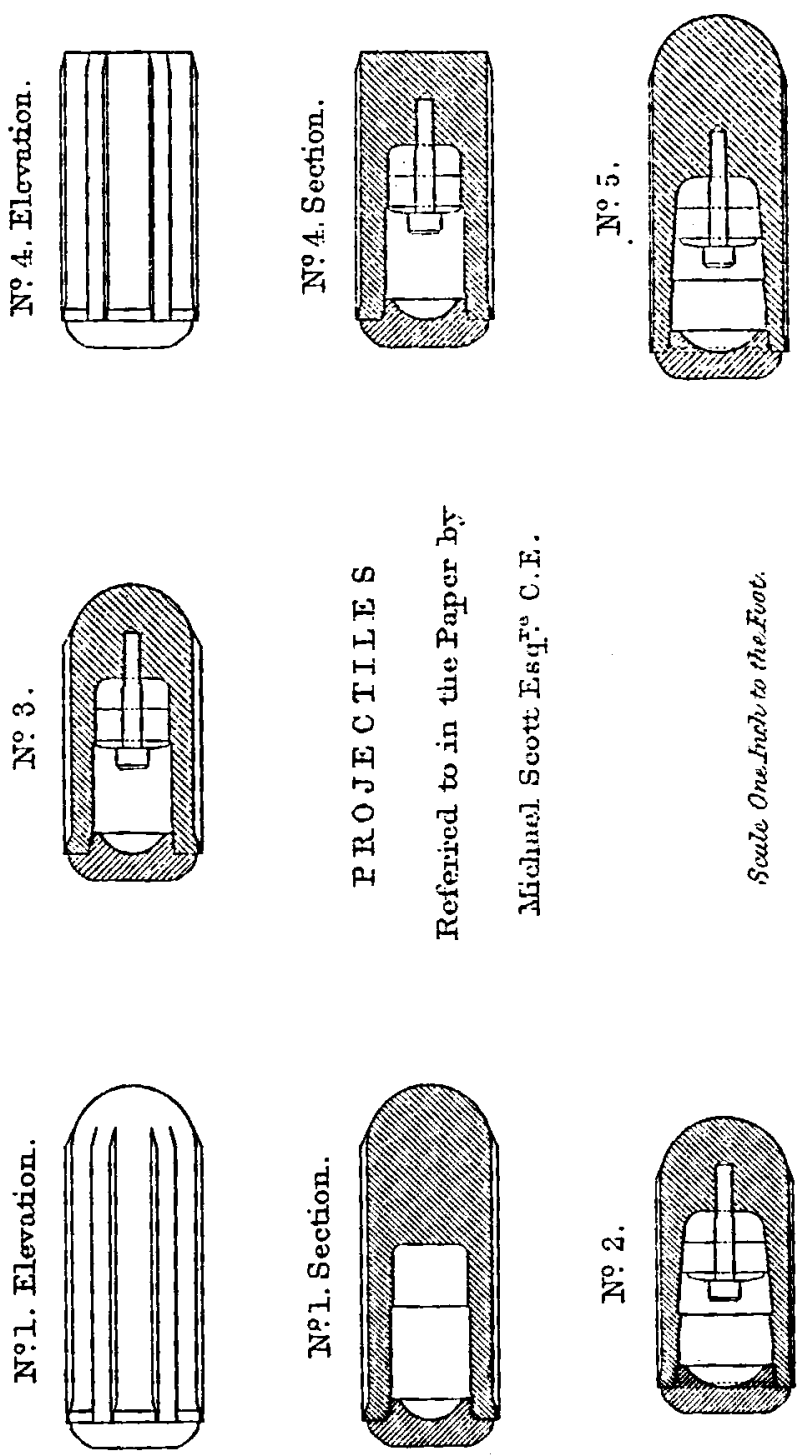
The experiment had never been tried, and, considering that it would be very interesting to know the result, the writer applied to the Sccretary of State for W War, and after an extended correspondence with the department, permission was obtained to have a few projectiles tried.

The projectiles referred to, represented by the drawings (seo Plate xv), were designed by the author in that year, and the trials took place at Shoeburyness in 1863 . The projectiles were found to be defectire in certain particulars, the most important being the want of strength in the hollow part of the shot and in the arrangement for correcting the centre of gravity. The nuthor having had no experience of the explosive force of gunpowder naturally underrated it, and the result was, that when fired with high charges, the metal of sereral of the projectiles broke, and in the whole of them, the arrangement for correcting the centre of gravity gave way.

Moreover, as will hereafter appear, from theoretical considerations, the complete bearing of which were not perceived until after these projectiles were designed, they were imperfect in form-the forward end boing either flat or hemispherical, and the backward end baving a swell. The gun from which these projectiles were fired was a smooth-bore, $6 \frac{1}{2}$ inches in diameter, but unfortunately the bore was not true, being wider at the muzzlo than it was further down about the trunnions, so that a projectile which passed easily into the muzzlo jammed hard near the trumnions, and it required the united efforts of a number of men to send the shot home. Unfortunately, also, the first projectile which was fired broke in the gun and scored the chase. Under these conditions it was not to be expected that perfect results would be obtained; nerertheless the experiments did establish points of somo importance. Disregarding the projectiles which broke in pieces, the first shot (see Plate, Fig. 1) that was fired weighed $104 \mathrm{lbs}$., the charge was $16 \mathrm{lbs}$., elevation $5^{\circ}$, the range 1,346 yards, the atmosphere was still, the lateral deviation was unfortunately not measured, but was supposed to be about 4 yards from the line of aim. This shot did not turn over during flight, and ricochetted in a straight line for a great distance.

In loading with the next projectile, it jammed in the gun near the trunnions so hard as to become immovable, and the experiments had to be discontinued, and the gun was sent to Woolwich to hare the shot withdrawh. Some months later the experiments were resumed. It was a sturmy day, with a high wind blowing across tho range so strongly that the author suggested that the experiments should be postponed; but the $\Lambda$ ssistant Secretary of the Ordnance Select Committee stated that, in estimating the accuracy, allowance would be made for the force of the wind, and the experiments proceeded.

The second shot (Fig. 2) weighed $81.3 \mathrm{lbs}$., the chargo was $12 \mathrm{lbs}$, the elevation $5^{\circ}$, the range 1,449 yards, the deflection to the left 40 yards, the initial velocity 1,333 feet. As the metal of this shot broke, little information can be obtained from the experiment.

The third shot (Fig. 3) weighed 83.7 lbs., the charge was $14 \mathrm{lbs}$, the elevation $5^{\circ}$; rango 1,391 yards, initial velocity 1,345 feet, the x 2 
lateral deviation 27 yards left. This shot did not turn over during flight, but it oscillated, and the rango was deficient.

The fourth shot (Fig. 4) weighed $94 \mathrm{lbs}$; it was flat headed; the charge was $14.1 \mathrm{bs}$; the elevation $5^{\circ}$; range 1,512 yards; deflection 29 yards to the left; initial velocity 1,280 feet. This shot did not turn orer in flight, and went with comparative steadiness, but chiefly owing to the great resistance of the flat end, and the fact that the initial velocity was not so high as it should have been, the range was limited.

The fifth shot (lig. 5) weighed $107.7 \mathrm{lbs}$., charge was $14 \mathrm{lbs}_{\text {, }}$, clevation $5^{\circ}$, range 1,433 yards, lateral deviation 24 to the left, initial velocity 1,230 feet. A piece broke off this shot, which, of course, affected the flight.

From these experiments, imperfect as they are, results of some importance have been obtained; for example, it was held to be impossible to fire.from a smooth-bore gun an elongated projectile, which would not turn over during flight; this has been accomplished, and, if in the case of one projectile, the principle may be considered as established; secondly, it will be observed that, allowance being made for the wind and the imperfections previously referred to, greater inaccuracy might have been auticipated, for, with a range of 1,391 yards, the shot grazed 27 yards to the loft-the direction in which the wind was bluwing; and with a range of 1,512 yards, 29 yards to the left; the deviation being what would be due to the difference of range.

Again, having regard to the small diameter of the gun in proportion to the quantity of powder, the initial velocities are satisfactory, for it has been said that a charge of $14 \mathrm{lbs}$. is more than can be beneficially burnt in a $6.5 \mathrm{inch}$ gun. This quantity has been stated to be a full charge for a 7 -inch gun, and to be in the same proportion the charge should be only $12 \mathrm{lbs}$. for a $6 \mathbf{6}^{\circ}$-inch gun. As compared with results obtained with larger guns, something would also be due to the inferior area of surface acted upon by the propelling forco; for example, this surface, which in the 6.5 gun is only 33.18 squarc inches, is in a 7 -inch gun $38 \cdot 48$.

The principal deficiency in the projectiles was want of range, accounted for in the case of the flat-ended shot chicfly by the grent resistance, and in the case of the others by the oscillation; and the author, therefore, proceeded to investigate the effect of different forms of cnds, and to inquire into the nature and causes of the oscillatory motion observed.

It has been stated that in order that an elongated non-rotating shot, moving in a resisting atmosphere, should not deviate from the true line of flight, amongst other elements, it ought to be perfectly symmetrical. 'This is true, so far as relates to the surface on which the air impinges; for should the forward end of the shot be not symmetrical, then it is evident that the pressure upon the surface would not be equally diffused. It would be greater on one side than on the other, which would cause the shot to deviate from the true line of flight.

But it appeared that the effect would be modified by rariations in the form of the surface on which tho air impinges. Take, for example, 
a hemispherical and a flat end. In the case of the first, crery part of the surface will have its influcnce, whereas in the case of the flat end it will be different, for it seems to the author that practically it is the edge of the cylinder which is important.
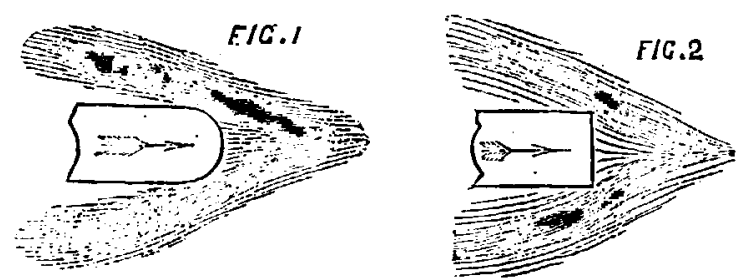

The diagrams represent, the supposed action of the air upon the two forms. With respect to the first, the influence of a projection on one side, in increasing the resistance, will be obvious. With regard to the second, it is believed that there would be a cone of air comparatively stagnant, and little motion across the face; but it will bo scen that there is a very great motion across the edge of the end, and, therefore, any irregularity of form hero would produce important results, which would be modified by another causo to bo subsequently referred to.

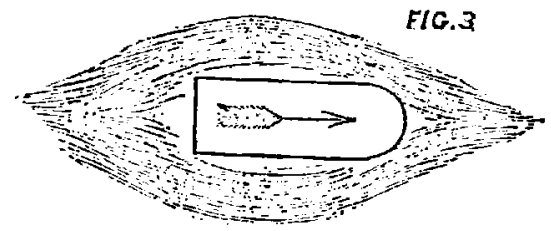

At high velocities the air outside the supposed cone is driven off laterally from the projectile, and may bo assumed to flow into tho space belind the projectile somewhat as shown in the diagram (Fig. 3), and as the after part of the shot is thus moving in a partial vacuum, it is obvious that perfect symmetry of that part is not of the importance it has been by some assumed to be.

The effects of tho wind of a passing ball shows the lateral dispersion of the air, and as a familiar illustration of the vacuous space left, may be mentioned, the case of a stick passed rapidly through water, when it, is seen that an empty space is left. The fact stated by Colonel Thiroux that the velocity of revolution of rifled shot is not diminished to the cxtent which might be anticipated, seems to confirm the view that the shot moves in a very attenuated atmosphere. A practical conclusion might be arrived at from this, namely, that continuous ribs in rifled shot would not meet with greater resistance than studs; and as the bearing surface in the former case would bo greater, the continuous ribs might have an advantage.

An important source of error in considering the flight of projectiles 
has arisen from assuming that the conditions are the same in the cases of large and small shot. This appears to the author to be a great mistake for before similar conditions can exist, and similar effects be produced, it would be necessary that the elements of length, diameter, area, and the velocity with which the projectiles are moving, should cach vary in some simple ratio, which is impossible.

For example, take two projectiles-one for a musket, ono for a large gun.

Suppose ench mores through 100 feet in a given period of time. Each projectile has, therefore, displaced a column of air 100 feet long and of its own diameter, and this space has to bo re-occupied and filled with air again.

Supposing that the projectilo had been moving inside a tube, the opening for the admission of air to fill up this space would be directly as the area of the projectile, but in moving through the atmosphere the condition is different, because the air flows in from the sides as well.

IIence it follows that the opening for the air to flow in, varies as the sum of the area of the end and the circumference of the sides; but this opening does not vary as the quantity of air required to flow in bohind projectiles of different sizes. It does not increase so rapidly as the quantity of air to be supplied, and hence, with u given velocity of flight, tho back part of a large projectile is moving in a much more attenuated atmosphero than a small projectile. All this shows the incorrectness of arguing absolutely from musket balls up to large projectiles.

The part of the projectile which specially requires to bo symmetrical is that part of the forward end upon which the air impinges, and over which it moves. This in a hemispherical end is a large portion of the whole surface, whereas in a flat end the intense action is confined to the extreme edge. In the case of the flat end, the air appears to be dispersed to the greatest extent, and, therefore, not only will this form meet with the grentest resistance from the air, but it will tend to produce a more perfect vacuum behind it.

The next point proposed for consideration was the nature and causes of tho oscillation observed in the projetiles designed by tho author.

The oscillation is supposed to be produced as follows: assume an elongated shot with a spherical end-when fired, if from any cause (gravity) the back end of the sliot tends to droop, there is nothing to check it until it comes in contact with the air, by which time it will have acquired a certain relocity, and it will, therefore, pass through some space beyond the position in which it might have rested before the downward motion is checked. Cousequently, having passed the line of quiescence, it is exposed to an upward pressure sufticient to produce upward motion, and thus it continues to oscillate in the vertical plane.

Another motion which the oscillation of the tail tends to produce may be called the plunging of the shot bodily. The cause of this appears to the author to be as follows: when the tail of the shot passes out of the true line of flight, the pressure of the air on the head 
of the shot is greater on one side than the other. If at the lower side, the shot tends to rise bodily; if at the upper side, to fall; and if the shot docs not turn over, a plunging motion is produced.

Turning to the forward end of the shot, it will be obvious that the form of end least likely to check the oscillation would be the hemispherical, and the form most likely to check it would be the flat.

It follows, therefore, that were regard to bo had solely to the steadiness of the projectile, the best form would be the flat end; but this form we know offers greater resistance than any other. The object, therefore, is to combine the steadiness produced by the flat ond with the diminished resistance arising from a modified form.

In dealing with the question of symmetry it was assumed that in the case of a projectile moring with high velocity there was a space of a conoidal form fillegl with comparatirely stagnant air.

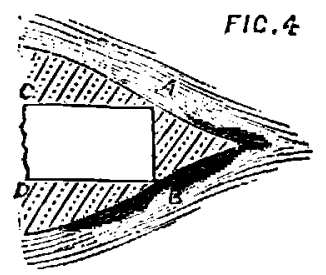

It is assumed that the pressure will bo greatest in the centre, diminishing gradually towards the sides.

It might, therefore, be possible to add to a flat-ended shot a bow of a conoidal form, as shown in the sketch, without materially increasing or diminishing the resistance. In the same way the body of the shot might be enlarged as shown in the sketch.

Further, the conoidal form of borv in adrance of the line $\Lambda \mathrm{B}$ would be attended with disadrantages; for, first, it remores the centre of gravity in the direction of the length, further back in proportion to the length, thereby increasing the tendency in an uncorrected shot to turn over.

Secondly. The steadying influence of the flat end is lost, and the part of the shot where greatest strength is required is made weak.

The part, therefore, in front of the line $\triangle B$ may be removed.

It lias been shown that the additions $C A-D B$ may be made to the projectilo without a proportionate increase in the resistance, and as this would give a larger capacity of shell and a heavier shot, this lateral addition may be made with advantage, and the form of the shot becomes that shown in the figures 5 and 6 .

Elongated shot for smooth-bore gun. Elongatcd shot and shell for 9-inch
mooth-bore gun.

5IG.5
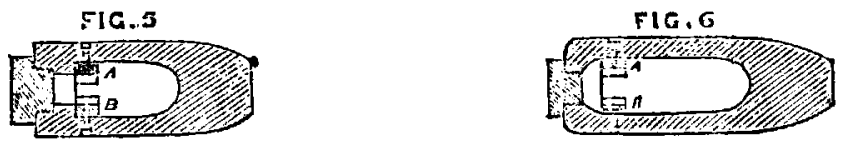
It has been stated that the form of end least likely to check oscillation in the shot would be the hemispherical, and the form most likely to check it would be the flat end. This depends upon a principle of resistance discorered by Mr. Froude.

Without entering upon the subject more fully, it will bo sufficient to state that Mr. Froude has found, first, that in the case of a plane moving through a fluid in the direction at right angles to its surface, the pressure is symmetrically distributed.

Second, that in the case of a plane moving through a fluid obliquely, the pressure is greater against the leading sido of the plane at $A$ than it is against the following side at $B$.

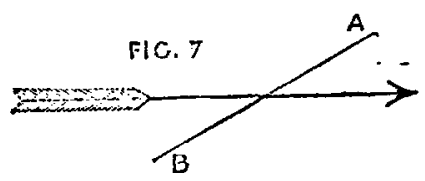

Now the first is the case of a flat-ended shot following the line of the trajectory, and the second is the case of the same shot moving at an angle to that line; and hence, if a flat-ended shot moves out of the true line, an increased pressure would be brought to bear upon the advancing side, which would tend to force back that side, and tend to bring the shot into the true line. Any deviation from the true line would therefore immediately be met by an altered resistanco tending to prevent such aberrations, and consequently the flat-ended shot tends to remain in the line of the trajectory, and not parallel with the axis of the gun; but this effect would not take place with the spherical end.

From what has been stated, it would appear to follow that it is questionable if some forms which have been adopted are the best for projectiles.

Iforeover, in the case of shot intended to be fired against iron plates, the pointed form appears to be objectionable for another reason, that the point would be smashed and the debris of broken metal interposed between the body of the shot and tho plate, thereby reducing the influence of the blow; whereas in the form proposed by the author the point is removed, and the shot will combine the punching effect of the flat end with the bulging effect of the spherical.

It will be obvious that, before one could estimate the practicability of employing elongated projectiles fired from smooth-bore guns, several other points would have to be carefully considered, and it is proposed now to idvert briefly to these.

In the case of spherical shot fired from a smooth-bore gun, with the ordinary windage, the effect is supposed to bo as follows:-The powder being first ignited at the upper side, a pressure is produced forcing the shot down upon the chase of the gun. Subsequently, when the powder is ignited at the lower side and the shot resting on the bottom of the chase, the gas escaping more freely through the mindage 
at the upper side of the shot, the pressure is greater at the lower side, and the shot is forced agninst the upper side of the chase.

In addition, the motion of the shot will be affected by the centre of gravity not being in the centre of the shot, and by friction. In the cisso of elongated projectiles fired from smooth-bore guns it is different; for, as the whole of the powder is ignited before the shot leares the gun, and as it is guided in its passage by the chase, it-docs not appear that the irregularity in the ignition of the powder would affect the accuracy:

The conditions in the case of an elongated projectile are quite different from thoso of a spherical shot. In order to sce this, let us trace the action throughont. Suppose the powder ignited as before at the upper side, the gas would rush out along the upper side of the shot, tending to press it down against the bottom of the chase; but the surface to resist this pressure, which in the splere was only a point, is in the elongated shot a line of considerable length. Therefore, although guns are damaged by this action in the case of spherical shot, it does not follow that they would be affected in the caso of the elongated shot. Then, suppose the whole of the powder is ignited throughout the whole depth of the charge, the tendency would be for the gas on the lower side to raise the shot; but if the shot were raised, the pressure would immediately be increased at tho upper side; and as this inequality of pressure can exist for only a very short distance from the tail of the shot, the head would hardly be affected; not so in the case of the sphere, where the whole semi.diameter is exposed to the lifting action of the gas, with nothing to resist it, becauso what in the elongated shot is a long line, in the sphere is a point.

What has been stated would be applicable to a shot which was not moving forwards; but when the tremendous velocity of projection is taken into account, the resistance of the air in front would combine with the pressure of the gas behind to make the shot move parallel with the chase.

FIG.8

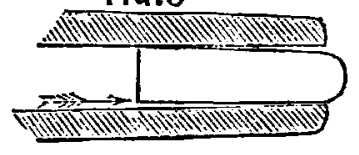

We have now to consider how the shot will be affected at the moment that it issues from tho muzzle of the gun. Take tho case as

FIC. 9

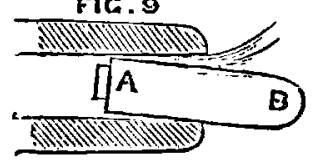


shown in the sketch (Fig. 9). The forward ond of the projectile is deflected downwards lyy the pressure of the escaping gas on the upper side, but to counteract this there would be the superior pressure against the lower part of the back end, in addition to the pressure on the forward end, which tends to keep the projectile from deviation.

$\Delta s$ it may be said that the pressure of the expanding gas on the upper side of the shot would act behind the centre of gravity, and thus tend to depress the back end of the shot, it should be remembered that to counteract this there would be the upward pressure against the lower edge of the plug.

Further, it is well known that gas of high tension expanding into the atmosphere can oxercise but very little pressure, becauso the great bulk of the power is absorbed in producing its own expansion.

Again, the tremendous momentum of the shot at the moment of its leaving the gun (being then at its maximum velocity) operating to keep it in a true direction, and the extreme minuteness of the period of time to which the shot could be exposed to the action of the escaping gas, should be considered.*

In the case of the projectiles which were fired and which did not break, as the difference in range can be accounted for by other causes, it does not seem that the escape of the gas affected the accuracy, and this with a gun which was bored wider at the muzzle than it was further down the chase; but even suppesing a bad effect were produced by the escape of the gas at the moment the shot left the gun, a simple remedy would be to place a ring of soft metal at the after end of the projectile, which would be expanded by the force of the discharge to fit the chase. This was in fact the arrangement adopted in ono of the carly forms of the author's proposed projectiles.

It secmed to the author reasonable to infer that if the resistance were diminished by a modification of the forms, such as is represented in the drawings, and if the hollow part of the projectile and tho arrangements for correcting the centre of gravity were made sufficiently strong to resist the force of the explosion, very superior results would be obtained; and with this riew, and considering that this system might be specially applicable to naval broadside guns, the author offered his plans to the Admiralty, stating that he was willing to carry on the experiments at his own expense. The authorities, however, did not think it advisable that any experiments should be made, and as it is impossible for a private individual to carry out experiments with large ordnance, the autlior regrets that he is unable to place before the Institution more perfect results, nor can he of course hope to prove the truth of a system by the firing of half a dozen shots.

Assuming that a range equal to the rifled projectilo is not obtained with the smooth-bore projectile, the advantages over spherical pro-

* Suppose the relocity at the muzzlo of the gun to be 1,600 feet per sccond, and suppose the action of the expanding gas to bo limited to the time the shot would pass over 3 inches - that is oriov the of a second ; furtlicr, suppose that the pressure of the expanding yas was equal to $\frac{1}{10}$ th of the pressure before issuing from the gun, and that it acted on the whole length and breadth of the projectile, tho result would be a dellection of the shot of $\frac{1}{\mathrm{~s} u}$ th of an inch.-M.S. 
jectiles would bo greater accuracy, increased capacity of shell, and superior strength.

As compared with the rifled elongated projectiles in the experiments, there was a deficiency of range, but with slightly increased initial velocity, which would make the penetrating power as great at closo quarters.

As the projectiles do not rotate, there would be no lateral devintion from that cause, and straight ricochet would be obtained.

There being only one trajectory* as against two in the case of the rille, with an unstable platform and the object aimed at in motion, it is believed that as great accuracy would bo obtained from the smoothbore.

. The smooth-bore would have the advantage of simplicity in the gun, and it is believed it could be more readily and more quickly loaded; the gun rould be durable, and neither gun nor projectiles liable to derangement or injury. Spherical shot, as well as grape and case, could also be fired from the smooth-bore, which, if fired from a rifled gun, would specdily damage the rifing.

The figures (5 and 6) represent smooth-bore shot and shell constructed on the principles which havo been enunciated. They may be constructed of cast-iron or of steel.

The drawings represent those of cast-iron.

For naval purposes it would probably be desirable to have projectiles of both metals, the one to be used against armoured ships, the other against ordinary ressels. The conoidal part of the head of the projectiles would be turned in the lathe; the centre of gravity be corrected by the two pieces of metal shown at $A$ and $B$. In the projectiles first made, this was effected by wooden dises having pieces of lead let in at one side, the shot being suspended, theso were turned until it hung.true between two points, which were proviously known to be in tho same vertical line, they were then secured by a bolt as shown.

$\Lambda$ s has been stated, this arrangement was far too weak, and gave way when the shot was fired.

It is proposed, therefore, to substitute pieces of metal secured in the manner shown, and which it is believed will stand the force of explosion of any charge withont disturbance. From the experience gained, it appears that the cost of correcting the centre of gravity of the largest shot would be very little; not above a few shillings.

It las been objected to the system proposed, that it can pretend to no advantage, not obtainable with shot of simpler construction fired from rilled guns.

In reply to this, the author submits that the proposed shot and shell are simple, there is neither lend-coating nor studs; as to cost, they might be made as cheaply as rifled projectiles, for the expense

- In tho caso of the smooth-bore, the shot mores in a curre in the rertical plane, whercas in the case of the rile, the shot has also to more in a lateral curre, making the actual path of flight the resultant of the two, a curre of double curvature, which appears to be not calculable.-M.S. 
of correcting the centre of gravity is little, and there is saving in other directions-this point deserves notice. Until a recent date the cost of the heaviest shot employed, such as that for a 68-pounder, was only a few shillings, and the addition to that price of two or threo shillings more would be a large percentage; but when wo take rifled shot weighing 300 pounds, even of cast-iron, the cost is considerable, and in this case the addition of a few shillings is a small percentage. Further, in the case of steel shot, the cost is enormously enhanced, and the proportion of the few shillings for correcting the centre of gravity, is correspondingly diminished. But more, the cost of the shot is the cost when it is fired, and the large charges of powder now cmployed involre a corresponding increase in expense, and in the caso of shell, the bursting charge would have to be added. Putting these items together, it will be found that the cost of correcting the centre of gravity is a triflo compared with the cost of modern projectiles fired, and if the slightest addition to accuracy could thereby be obtained, it appears to the author that it would be well worth the money.

In conclusion, the author would add that, of course, there is no intention, on his part, to speak dogmatically upon a subject so full of difficulty; his desire is to submit these ideas to the Institution, in the hope that they may lead to discussion on the part of those who are more competent to deal with such questions.

Commander Cozourb, R.N. : I should like to asl two questions which hare suggested themselres to me. Firstly, I did not quite understand whether the mere correction of the centro of grarity was sufficient to prerent the shot turning orer. Secondly, I do not think it was quite clearly made out bow the altercd shape of the shot would be sufficient to correct the oscillation which the lecturer stated occurred with the hemispherical-headed shot.

Mr. II. ScoIT: In answer to the first question I think I staled that there was more than the correction of the centre of grarity required. I hare talen up the subject at the point where it was left in a pamphlet which $I$ published. I. did not desire to go orer the same grouud, for I dare say many gentiemen present arc acquainted with it; and it would hare been tedious to discuss the same question again. But it was stated that the correction of the centre of grarity and the perfection of the symmetry mere both required. I am unfortunately unable to stato what effect this modification of tho form would hare had. I wish to hare it triecl. The original forms wero only two, the hemispherical and the flat. Wo found that neither of them mas satisfactory. I then proposed to modify these forms for the reason given in the paper, and to make then liko Figs. 5 and 6 . I applied to the Gorcrnment for an opportunity to try a shot of that form, but that offer mas unfortunately refused. Therefore it remains a question whether it would hare the desired effect or not. I hare stated my reason for thinking that it mould bo an improrement upon prerious forms; but as to whether it would remore the oseillation altogether is quite another question.

Captain TrLen, R.E. : I hare always understood from MIr. Whitworth's experiments, -in fact from all experiments that haro been made, - that one of the first principles of projectiles was that when you departed from the spherical form and began to elongate the shot, unless jou began at the same time to rifle your gun in order to malo your shot rotate, the projectilo at once began to show symptoms of turning-orer; and funther, that the more elongated the shot ras, the more that tendency cxhibited itself. I had the pleasure of being in Mr. Whitworth's galler, and seeing some of his carlicr experiments ; and I remember at that time that the pieces of paper which he placed at interrals across tlic gallers showed the points at which the projectiles turned on their sicles; and showed very 
distinctly that when, as Mr. Whitrouth originally proposed, he clongated his ghot to an unusual extent, he was at the same time obliged to increase the number of turns in the gun in order to orercome the tendency of the shot to fall on its side instcad of going straight forward. Now, if what Mrr. Michasl Scott has stated is correct, it mould appear that he has the idea that ho can, by merely balancing his shot, ovcreome that tendeney.

Mr. MI. Scorr: The cases are hardly parallel. MTr. Whitworth's shot mere golid; consequently the centre of gravity would be far back. $\mathrm{II} 5$ shot are hollow behind; and these two shot on the table were actually fired and did not turn over. They lave a considerable length in proportion to the diameter. But it is not a parallel caso quite with shot that are solid throughout.

A Mesiben: Werc any practicable means taken to rerify that the shot did not turn orer?

JIr. MI. ScoTt: In this way: First we saw them throughout the flight. But there was a better proof than that: The range sergeant who had the noting of the grazes stated that in this case the graze was a long slallow scoop in the sand; so that eren when the shot touched the sand, it did not turn orer.

Captain TrLen: I dare say MIr. Whitworth, who has had great experience in these matters, will kindly tell us whether ho has obserred that anything of this gort can be produced: that it is possible to fire an clongated shot that shall not turn orcr without at the same time giring it rotation.

Mr. Whirmontय: I will state that I nerer fired an elongated shot without giving it rotary motion. I haro nerer tried the experiment; but I know this rery well, that if you gire a small rotary motion to elongated shot it will turn orer, and that the longer the shot is, the more rotation you must giro it.

Captain Truen: That is what I understood from Jour carlin experiments.

Captain Borgess : Protided it is solid.

Mr. Wmirwontm : No matter whether it is solid or hollow.

Captain Colours: Ono would suppose that if the rear-end of the shot wero much lighter than the fore-part, the tendency to turn orer must be proportionately reduced.

Mr. A. Scorr: That may be true in its degree; but if the centre of gravity is not in the centre of the figure, tho condition you suppose would not be sufficient.

The Crammax: You will doubtless allow mo to gire your thanks to Mr. Scott for his contribution to the science of projectiles. After what MIr. Whitworth has said, that he has nerer tried the experiment mentioned, his statement can be no negative to what has been tried. The experiment has been made, and it really appears to me to answer satisfactorily. It is unsatisfactory that such a gun as the one described, which was imperfect, should hare been supplied for such a purpose; but it is only what wo have liad to say before with respect to the guns that rere employed for the spherical shot. They, were the most rough, we might eren sas, disgraceful guns. There was no real comparison, no scientific comparison, no skill, no care there. We hare pretty much the same thing here. The gun which MIr. Scott has described in the paper was so unequal in the bore that the shot jammed near the trunnions, and it took considerable force to get it home. A part from any defect in the gun, we must hare expected oscillation in the projectile. Therefore it was an experiment all against the projectile. If the gun had been better suited to the purpose, the projectile, as we might reasonably hare expected, would hare giren better results than it did. Howerer, this paper is a contribution to the science of projectiles. It is interesting to knom, that that which had been conceired to be impossible, is not, so far as we can rely upon MTr. Scott's information, impossible; that an clongated shot can be projected, and that it will not tum orer, if the adjustments are had respect to. It is interesting in this respect too, that with his balanced shot a much higher initial relocity is obtained than from the clongated rifled sliot. Although there was a deficiency in the range, that deficiency scems to hare arisen from the greater oscillation. But if jou had a perfect gun you might reasonably expect that that oseillation would bo materially redueed, and that the range would be materially increased. We have heard admissions lately made at the Institution of Naral Architects with respect to initial relocity; and, by the way, 
wo should hare heard nothing at all about that, if it had not becn necessary to support a particular forma of construction of ressel. Thoso who wero belind the scencs trere let into the secret, and thej were told, with regard to a certain experiment, that there was a different description of powder used, and a different initial relocity obtained to that which was reported. But, surely; this is rery unsatis. factory. It easts a doubt upon all theso experiments. The initial relocity giren here, not obtained by MIr. Scott himself, mas be incorrect, but it is comparatively correct, and is greater than the initial relocity obtained from the elongated shot; and as it was stated at the Institution of Naral Architects that the difference of initial relocity, though not great, made a differenco of an inch of iron in plating, it becomes a rery scrious and a rery important question. It is desirablo to get higher initial relocitics with safety, particularly when ro see the number of guns that gire way with large charges. The Times to-day mentions MIajor Palliser's gun. I do not know what initinl velocity it gires; but it is quite clear that initial relocity is one of the prime elements for an effectire gun. Thereforc, anything that will belp us to get that rithout bursting the gun is a desideratum. It cannot be but that in rifling the gun, and especially in using studs on the ehot, the gun must bo materially weakened; therefore, in that proportion with guns so scored, it is impossible to fire large charges. The gun for theso shot has no score, therefore it is proportionably stronger. Considering the measure of sucess MIr. Scott has obtained, it is a waete of money to mako experiments in this way. It is rery strange; when a man undertalies to pay tho expense of these experiments himself, in order to solve problems in ecience which inrolve such results as these, that he should not be supplied with a proper gun. Howerer, be that as it may, wo have to thank Mr. Scott for his interesting paper. 